\title{
Desperately seeking ... oder P wie Peripherie
}

Dominik Heim

Korrespondenz: PD Dr. med. Dominik Heim Chefarzt Chirurgie Spital Frutigen CH-3714 Frutigen dominik.heim[at]spitalfmi.ch
Es gab Zeiten im «English book corner», da lagen sie alle auf, die Ludlums, die Forsyths, die Crichtons und die Folletts. Auch John le Carré gehörte dazu, nein, gehört, denn der Altmeister legt mit $A$ delicate truth 50 Jahre nach The spy who came in from the cold (1963) nochmals nach. Etwas verschlungen zwar, etwas kompliziert. Und man verzeihe mir die Behauptung - etwas mehr «straight forward» waren die Alten schon und auch spannender. Aber da war alles noch etwas einfacher. Schliesslich herrschte noch der kalte Krieg, in dem sich der russische Agent im Speisewagen enttarnte, indem er Rotwein (!) zu Fisch trank (James Bond: From Russia with love, 1963).

Jetzt ist vor nicht allzu langer Zeit ein Neuer hinzugekommen, ein Unikum fast, ein Kuriosum, denn die Geschichten spielen in Frankreich, und die Buchsprache ist englisch. Europa ist so fasziniert davon, dass man mit organisierten Busreisen ins Périgord zu den Stätten seiner Romane an die Ufer der Dordogne pilgert. Martin Walker heisst der Neue, und er hat soeben seinen sechsten Roman The resistance man, vorgelegt. Jetzt liegt Walker dort, wo früher eben die Clavells und die Cusslers ausgestellt waren. Und Donna Leons commissario Brunetti in Venedig hat mit Bruno, the chief of police in St-Denis, sein französisches Pendant erhalten.

Und wo ist jetzt diesmal der Bezug zur Medizin? War es bei meinem letzten Beitrag das Remake im Film und die Rückbesinnung auf die Empirie, so ist es diesmal die Peripherie, die französische Provinz, die so schön kontrastiert zur Stadt, zu Paris, wo alles schneller, effizienter (und besser?), aber auch kühler und unpersönlicher ist. Diese Peripherie gibt es bei uns auch, und Brunos provinzielle Sorgen kennen wir. Der kleine Dorfladen verschwindet und die grosse Migros kommt. Die Konditorei (mit den besten Florentinerli der Region - meine Hommage an die Geschwister Schenk in Frutigen) und das kleine Café um die Ecke verschwinden, und Starbucks Coffee

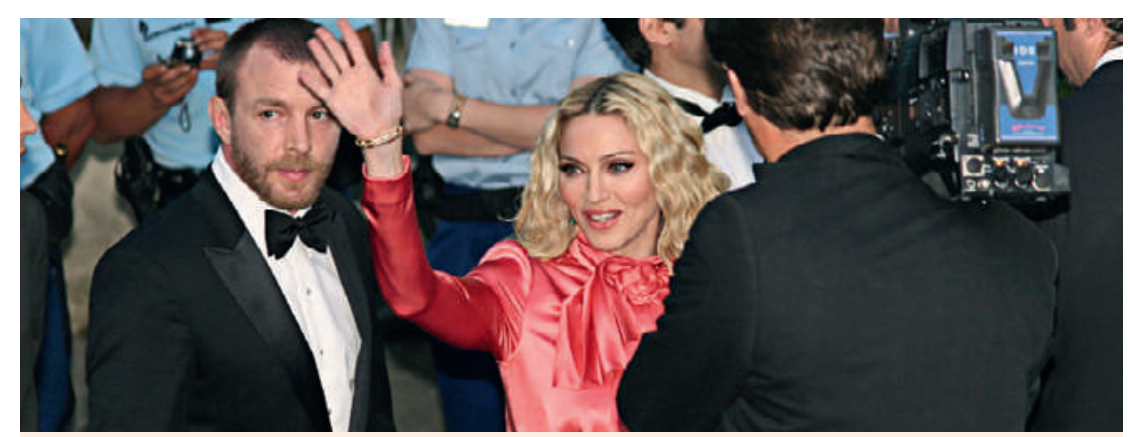

Der Film «Desperately seeking Susan» machte Madonna berühmt. Heute gilt: «Desperately seeking doctors.» kommt. Und - da gibt es noch die kleinen Spitäler und die Hausarztpraxen in der Peripherie, auf dem Land, in den Hügeln und im Bergtal. Bürokratische Zwänge, gesetzliche Vorschriften und veränderte Abrechnungssysteme bedrohen jetzt diese provinzielle Idylle, sofern man diese Situation als idyllisch sieht. Denn nicht ungern etikettiert man diese Provinz auch etwas mit einem Hauch von kulturarmer Verstaubtheit, von Rückständigkeit und von «nicht mehr à jour»-Sein. Und so ist es schwierig geworden, medizinische Nachfolger in diese periphere Situation zu finden. Es verlangt eine breite Ausbildung, es verlangt die Bereitschaft, häufig da zu sein, es verlangt auch die Bereitschaft, aktiver Teil dieser Peripherie zu sein. Anonymität ist schwierig. Der Landarzt, der Chirurg/Mediziner am kleinen Spital ist wie Bruno, der Dorfpolizist, eine erkannte Person. Dafür kennt man dann gewisse Zusammenhänge, man kennt die Geschichten, und man kennt die Patienten. «Local knowledge is a wonderful thing. I don't know what we'd do without it», schreibt Walker. Wie das doch auch auf die Medizin zutrifft!

Die heutige Zeit ruft zwar nach Globalisierung, nach Bündeln von Ressourcen (auf dass es billiger werde), nach Poolen von Seltenem - und das Zuletztgesagte macht ja auch Sinn. Daneben aber gibt es das Häufige. In der Chirurgie ist dies die Allgemeinchirurgie, die Chirurgie eben des Häufigen und des Alltags. Diese Chirurgie und diese Medizin - mit ihren Grauzonen zu den Spezialitäten - in einer gewissen Peripherie zu erhalten, das sollte doch eigentlich bei entsprechender Einstellung und Ausbildung auch Sinn machen. «I'm happy here ... I'm busy, I think that I'm useful, and I live in a place that I love among a lot of people that I like. It's a way of life that pleases me ...» sagt Bruno zu seiner Freundin Isabelle, die es nach Paris zieht. Es sind solche Nachfolger, die für die weissgewordene Mediziner-Generation in der Peripherie jetzt dringend gesucht sind. Desperately seeking Susan (1985) hiess der Film, mit dem Madonna berühmt wurde. Desperately seeking doctors!

Und um es in musikalischer Allegorie ausblenden zu lassen: Es ist hocherfreulich, dass die ergrauten Black Sabbath dreiundvierzig Jahre nach ihrem Debutalbum auf «13» immer noch so wuchtig, grob, hart und gradlinig daherkommen. Und es regnet gar am Schluss im Stück Dear father (2013), so wie alles im allerersten Stück Black Sabbath (1970) mit Regen, Donner und der Kirchenglocke begonnen hat.

Aber - man geniesst jetzt auch die neue, rauhe Stimme von Alex Hepburn, und freut sich, dass die früh verstorbenen Janis Joplin und Amy Winehouse eine Nachfolgerin gefunden haben. 